\title{
The Dialectics of Maria Zlotina
}

\author{
Yuriy Myelkov
}

Charity Organization "Center for Practical Philosophy"

Frolivska Str. 1, 01001 Kiev, Ukraine; yurimelkov@univ. kiev.ua, tel. (0038-044)-238-65-23.

\begin{abstract}
In this paper I review the system of dialectical philosophy of Maria Zlotina, one of representatives of Kiev school of Russian and Ukrainian philosophy of the $20^{\text {th }} \mathrm{C}$. That philosophy is an original conception of materialist dialectics, where the process of cognition appears as the reflection of objective development process of the reality. Development is presented as self-motion of the object out of its inner contradiction, in which process oppositions of chance and necessity, whole and part, determination and indetermination, singular and general are being dialectically resolved. It is stressed that universality of dialectical method lies in it demanding to consider each specific moment in concrete way. The conclusion is made that dialectical method of cognition is in demand and is presumed by contemporary science of selforganization and general current of contemporary philosophical
\end{abstract}

thinking, particularly, in order to understand specificity of situations of complexity and instability.

Keywords: dialectics, development, contradiction, selfdetermination, Soviet philosophy

Acknowledgement: This paper is based on research done within the framework of the project 'Human Strategies in Complexity: Philosophical Foundations for a Theory of Evolutionary Systems' (http://www.self-organization.org) funded by INTAS (\#0298) and supported by the Austrian Federal Ministry of Education, Science and Culture.

\section{A Word on Soviet Philosophy. The Kiev School.}

The philosophical tradition of the Soviet times is a special object for investigation. Some contemporary researchers consider it to be of no importance, being only pure ideology that has nothing to do with philosophy. However, this point of view is totally incorrect. First of all, Soviet philosophy is in no way a monolith of ideology or dialectical materialism; it included a variety of different directions and points of view. Furthermore it must be said that dialectical materialism itself as the center current of Soviet philosophy has also introduced some brilliant ideas, both topical and profound. The problem however is that the way of expressing such ideas differs widely from that of the contemporary philosophical tradition.

This difference is implied by specific circumstances of the Soviet era. While usual complaints of censorship and ideological oppression concerning dialectical philosophy are somewhat exaggerated, one must not forget that the style of Soviet philosophical thought was still to obey the rules laid out by party authorities. Thus, for example, no philosopher could present his/her ideas as something new; they rather had to offer their theories as some form of comments to the works of "classics" - Marx, Engels, and Lenin. For some time Stalin was the final branch of that pattern of "greatest philosophers", and it must be noted that during that period little that was attractive happened in the field of dialectical philosophy. However, starting from 1950s and 1960s the philosophical life in the Soviet Union abounded in vitality. It is interesting to note that several schools of philosophy appeared in major university cities of the country. 
While developing mostly out of the 'core' of dialectical materialism, those philosophical schools were most successful in investigating such spheres that were more free of ideological oppression, like science. Several regional schools had their fundamental base in the concept of activity (activity approach). This principle allowed the philosophers to depart from 'official' subject-matter of 'the main question of philosophy' - that is, the relation of idealism and materialism. The activity approach made it possible not to concentrate the investigation on the problem of the 'primary / secondary' place of materialism or idealism, but to research the process of transition of subject into object and the reverse process of transformation of objective into subjective and theoretical. Such investigations in turn required the accurate use of dialectical method.

The Kiev school was one of those regional Soviet centers of philosophical activity, of dialectics, philosophy of science and philosophy of humans and the world. The most prominent figures of the Kiev school, and its 'founders', are Pavel Kopnin and Maria Zlotina, professional philosophers who came to Kiev from Moscow. In the capital city of the Ukraine they not only conducted their most important research, but also have educated several generations of philosophers, who still continue their work and keep on their traditions in different areas of investigations.

The aim of this paper is to present the basic concepts of Maria Zlotina, who was one of the most prominent representatives of Soviet dialectical thought. The reasons for addressing to her philosophical heritage are the following. While the works of other outstanding Soviet dialectical thinkers of that time, like Evald llyenkov, Alexander Zinovyev (both of the Moscow school), and even Pavel Kopnin are rather widely distributed and have been translated into several foreign languages, theoretical works written by Zlotina are still little known even in Kiev. Maria Zlotina was predominantly a teacher, a 'peripatetic' philosopher. Except for several fragmented articles and brief 'methodical' editions that were published in paltry numbers in 1960s and 1970s, her ideas systematically presented in her Doctor of Science's dissertation "General Laws of Development and the Reflection Principle" (Zlotina 1969) have not been made public during her lifetime. It must be noted that patterns of the development process, brilliantly and religiously reviewed by Zlotina in her dissertation on basic dialectical categories, form that circle of ideas that is most demanded by contemporary philosophical thought, which now turns again to the method of dialectics.

This demand is mostly related to the necessity of understanding and elaboration of the philosophical foundations of the contemporary science. According to Irina Dobronravova, who herself was one of the most beloved pupils of Maria Zlotina, "The irony of historical fates of dialectics is that when on our territory the ideological backing of dialectics had fallen off, its time has come: the scientific revolution of the two last decades of the $20^{\text {th }} \mathrm{c}$. made self-organized systems a subject of nonlinear science. Self-organization as the becoming of a new whole required for its comprehension the corresponding dialectical categories of thinking" (Dobronravova 2001: 129). The new image of reality appeared before us as a result of discoveries of synergetic and other contemporary scientific approaches forces us to turn to the investigation of such philosophical categories as chance and necessity, whole and part, ground and grounded, which are required in order to understand the behavior of complex systems under instability at bifurcation points, in order to understand the causes of the emergence of new phenomena. Here the tradition of dialectical materialism, and the dialectical philosophy of Zlotina in particular, has a lot of ideas to share.

Maria L'vovna Zlotina was born in Moscow in 1921. She started her philosophy education at the Moscow Institute of History, Philosophy, and Literature (the best institute of humanities at that time), but in 1941 she volunteered to go to the front as a nurse. Zlotina was heavily injured there but luckily survived and finished her higher education after the war at Moscow University. In 1947 she arrived in Kiev, and for more than forty years worked as a lecturer and Professor at the Institute of Postgraduate Education of Kiev University. She retired in 1993 and died in 2000. 


\section{The Subject and the Nature of Dialectics. The Notion of Development}

The question about the nature of materialistic dialectics and its subject evoked controversies even during the Soviet times, in spite of the official state of dialectical materialism as 'the Weltanschauung of the Marxist-Leninist Party' and the whole working class. One of articles in the collection of papers on 'fates of dialectics', dedicated to the $80^{\text {th }}$ anniversary of Maria Zlotina, characterized Kiev philosophy school and its representatives such as Zlotina, Kopnin and Shinkaruk as those who revived the tradition of dialectics as logic and theory of knowledge, in opposition to "Stalin's interpretation of dialectics as a science of general laws of nature development, which (laws), by the way, do not exist and have never existed" (Shevchenko 2001: 271).

Such a characterization of the Kiev dialectical tradition is nothing but dubious. The point is that contemporary critics of dialectics (and not only them) use different meaning for both law and development, which are superficial and abstract and have nothing to do with dialectics. The very title of Zlotina's dissertation contains both of those notions, which are central to Soviet dialectical tradition. By the way, Stalin himself never used the notion of law in his 'dialectical' paper. Stalin saw dialectics as just the method for studying natural phenomena. As for the category of development, it does not bear any philosophical content but it is used in ordinary way. Nature as considered by dialectics, says Stalin, is presented as not stagnation and immutability, "but a state of continuous movement and change, of continuous renewal and development, where something is always arising and developing, and something always disintegrating and dying away" (Stalin 1941: 537).

The thesis on dialectics as a 'science' of general laws, which is now heavily criticized, belongs to Engels: in order to provide a popular explanation, he states in Anti-Dühring that dialectics is "nothing more than the science of the general laws of motion and development of nature, human society and thought" (Engels 1961: 145) ${ }^{2}$. And while not in Stalin's works, this idea has been repeated many times in popular editions. "Marxism is the science of laws of nature and society development..." (Alexandrov 1954: 3 ) - that is the first phrase of the "Dialectical Materialism" textbook (1954). Accordingly, dialectical materialism is the study of the most general development laws, not replacing natural and social sciences, but synthesizing them on the base of their discoveries.

At the same time such an attempt to position dialectics as 'the most general science' aroused criticism from both left and right - and that were so called 'red positivists' and 'red existentialists' - the two unofficial currents in Soviet philosophy of 1960s. It is interesting that both of them were discontented with dialectics' role as the general method of both science and humanities. The positivist partisans perceived it as an excessive ideologization of science, an attempt to limit the freedom of scientific search. On the other hand, 'red existentialists' feared the restriction of the freedom of human that was imposed by some external and universal laws. The latter idea is widespread today: the very notion of law, as something related not only to the external world but to society, is rather replaced now by idea of 'scenario' in philosophical thought. However, I think that such a hostile attitude toward dialectics and its 'general laws' arises from a misunderstanding of dialectics - and we will get back to this point several times later.

The most hostility was and is evoked by Engels' view that the distinctive feature of dialectical materialism is dialectics of nature. As stated by M. Merleau-Ponty dialectical materialism discovers dialectics where it could never be - in object, in being; "If nature is nature, that is, exterior to us and to itself, it will yield neither the relationships nor quality need to sustain a dialectic" (Merleau-Ponty 1964: 126). Similar ideas are expressed by Kiev existentialist Igor Bychko, who says that Engels vulgarized Hegelian dialectics: "'Moving'... the dialectics from subjective into objective world, Engels applies dialectics - that spiritual phenomenon in principle - to incommensurable medium. That's why so called 'materialistic' dialectics (as first of all the dialectics of 'nature') is a certain philosophical 'centaur', a sort of 'wooden iron'" (Bychko 2001: 104).

\footnotetext{
1 "Sondern als Zustand unaufhorlicher Bewegung und Veranderung, unaufhorlicher Erneuerung und Entwicklung, in welchem immer irgend etwas entsteht und sich entwickelt, irgend etwas zugrunde geht und sich uberlebt".

2 "Nichts als die Wissenschaft von den allgemeinen Bewegungs- und Entwicklungsgesetzen der Natur, der Menschengesellschaft und des Denkens".
} 
Pavel Kopnin, when answering such critical comments about for dialectical materialism, stressed that dialectics is a method, but method here is not a simple sum of rules, which is an incorrect understanding of it. The materialistic approach supposes such study of the actuality (Wirklichkeit) that depends upon the specific laws of that actuality. Dialectics turns out to be the universal method just because it provides the knowledge of the most general laws of natural development that have an effect everywhere, but the law's effect is refracted through the originality of singular (Einzelne) phenomenon. In other words, dialectics has nothing to do with abstract schematism, and only concrete application of dialectics under concrete study of the actuality will provide for the success of cognition.

In Zlotina's philosophical system the methodological universality of dialectical materialism is revealed through the set of categories. Hence Zlotina begins her investigation from the notion of development. As the universal development process forms the subject of dialectics, dialectics differs from other disciplines by its field of study: development could not be presented here as just one kind of change, along with others. "That is, the very 'subject field' of dialectics has such specificity that transforms its categories into universal forms of knowledge" (Zlotina 1969: 7).

Dialectics is defined as not only 'teaching of development' but 'teaching of connections' as well, and the subject of dialectics is not just any connections but the universal connection in the development process. All dialectical categories reflect on both the kind of connection and development process; they appear as forms of knowledge of development. Connections are materially realized through motion in the diversity of its forms. That's why dialectics could not be ontology. The 'ontological side' of dialectics is the issue of objective content of its categories.

The first category of dialectics is the category of development. Upon searching for its adequate definition, it is found, according to most philosophers, that the closest generic notion is the notion of change. Attempts to define the specific aspects of development lead to various results: 'qualitative change', 'irreversible change', 'motion from simple to complex', etc. However, Zlotina says, there notions of development are defined merely ontologically, irrelative of a concrete system of notions. One cannot define development by pointing to only one specific aspect of the process. Dialectics presupposes comprehending development as the unity of opposites - "and, therefore, as the unity of qualitative and quantitative, irreversible and reversible, progressive and regressive" (ibid.: 10). That is, for Zlotina, development is not just the change, but the unity of change and preservation.

The opposite point of view to Zlotina's notion is that of 'red positivism' - that development is the subject of special sciences, the obtrusion of 'universal laws' into science is considered as an attempt to give a single-meaning answer to the content of development, as a 'needless claim of philosophy on the role of science of sciences'. However this means only that, in Zlotina's terms, dialectics is not a universal ontology, and the notion of development could not be defined abstractedly, irrespective of concrete system of categories. "To reveal the essence of development is to reveal its laws. But the process of motion toward essence presupposes a definition of qualitative specificity of phenomenon... with nothing could be said about it if it is considered abstractedly..." (ibid.: 17). In that case, when the notion is considered outside the system of notions, the problem of its definition is transformed into scholastic dispute over words.

As Kiev dialectical philosopher V. A. Bosenko shows, the category of development mirrors the essence of motion of the matter as its way of existence revealed by dialectics. That's why distinguishing between notions of motion and development is possible only by means of epistemology: development is the way to extend knowledge of essence of matter's motion as its self-motion. Zlotina agrees here with Bosenko, however she criticizes him for running to the other extreme: trying to master the empiricism, the investigator arrives to define dialectics as 'self-constructioning'.

If the first positivist approach denies the possibility of making a general philosophical theory of development, then Bosenko approach leads to isolating dialectics from the real development process. Both extreme points are inadequate for materialistic dialectics that considers the general (Gemeine) as just a stage toward knowledge of the concrete. Dialectics - and here Zlotina makes common cause with Kopnin - must interact with empirical science not for being confirmed, but in order to develop itself. While 
pointing science toward 'self-criticism', dialectics itself has to contain self-criticism - only then it could serve as the universal (Allgemeine) method.

Under materialistic dialectics the notion of development appears as an expression of the essence of matter's self-motion, as a reflection of the inner necessary tendency of that process as a whole, which is specifically realized in the motion of concrete systems under concrete conditions as a historical process. For Zlotina, "The universal methodological significance of the philosophical notion of development lies not in the task of discovering within any individually taken object an effect of 'all three laws of dialectics', and, having not found them, to exclude them from the development process, - but in the task of comprehending the given 'object' as a moment or side of the universal process" (ibid.: 24). That is, first, dialectics is by no means an abstract scheme (or its critics would be right), for as a universal method it teaches us just to consider every natural or social object not as it is 'by itself', but as it appears under the system of objects' connections that in turn expresses the essence of that object as the process of development, development of both nature and society. Secondly, the universality (Allgemeinheit) of dialectical laws does not mean their most abstract nature - quite the contrary. Dialectics as the universal method, first of all, directs us to knowledge of the concrete.

In other words, the laws of dialectics themselves contain, besides the general moments, the moment of the particular (Besondere). "Laws of dialectics do not objectively have effect as specific laws of nature, society or thinking, but they manifest their effect as specifically general according to one or another sphere of actuality. It is this objective connection of general and specific in dialectical laws' effect that finds its expression in the abstractions it creates. The particular in laws of dialectics is a special form of manifestation of the general" (ibid.: 27). That is, the methodological universality of laws of dialectics consists in the fact that their own use for analysis of concrete phenomena necessarily presupposes taking into consideration the specificity of those phenomena! That's why dialectics could not be considered as 'a universal picklock', by the beloved Zlotina expression, because the concrete development process of a concrete object never entirely coincides with development laws.

That moment is explained by the double nature of dialectical laws themselves: in addition to essence, that is, the inner necessary tendency of change in the given direction, a law also has a form determined by concrete conditions of essence's realization. That is also true for dialectical categories: their objective content corresponds to the objective content of their system. "Each category is filled with objective content being an element of the system, a certain stage of reproduction of the objective development process in thinking" (ibid.: 30). At the same time, dialectics as the system of categories is an open system, that is, there is no single-meaning consistency of categories. However this moment of openness (noted already by Marx and Lenin) must not be presented as absolute one (like it is in Bosenko's theory), for a system open to all processes taking place in the medium is not really a system, as it is stated by Moscow philosopher Nikolay Ovchinnikov.

That's why Zlotina while dedicating her investigation to the study of dialectical categories, points out that she is going to talk not of the system of categories, but of the reproduction of development laws in the categories. As a rule, the categories of dialectics are revealed in pairs, however relations of the paired are always mediated by the whole system. The pairedness of dialectical categories is the logical expression of their contradiction, but dialectical contradiction is mediated by other, intermediate categories under the concrete knowledge system, and it is owing to it that categories obtain their concrete content.

The category of development in its most abstract form can be reproduced in pair of categories: 'ground' and 'grounded' (Begründet). Zlotina shows that development is the process of enriching the ground, and it is reproduced in the thinking movement from abstract to concrete. The grounded is "richer than the ground, for in the process of development the ground is being joined by conditions... The ground is a simple undeveloped integrity of the object, some substantial actuality, a moment of the beginning of development, which gives a result in the form of the grounded, when passing the way of grounding the latter. In this connection essence can be defined by category of content and category of appearance" (Zlotina 2001: 23). The source of the development in the ground is the contradiction. 


\section{Development by contradiction. Self-motion and self-negation. Dialectics of the particular}

At the heart of dialectics as the theory of development lies the acknowledgement of the inner contradiction of phenomena being the source of their self-motion. The category of contradiction is central for materialistic dialectics and requires the same carefulness in its definition as the notion of development. It is a false understanding of this term inherent, as Zlotina notes, to all critics of dialectics since Dühring that leads to the denial of contradiction as the source of development.

Contradiction in the nondialectical sense is often equated with simple incompatibility of opposites. More precisely, such comprehension is 'dialectical' regarding 'negative', 'tragic' dialectics based on antinomies from Kant to Adorno. Materialistic dialectics presupposes a different understanding of contradiction. According to Zlotina, just as the notion of development cannot be understood as a kind of change that exists along with other kinds, in the same way contradiction cannot be considered as only one kind of real correlations, along with coordination and harmony - such an understanding would be too narrow and wrong. Contradiction is not 'non-coordination, just like development is not 'progress' or 'change'. The matter concerns not so much contradiction as a relation between objects (that can really be reproduced in terms of coordination / non-coordination). It is a more profound consideration of contradiction that is meant here - contradiction as a contradiction of one object, here the object itself is considered to be the contradiction, and contradiction here is a process, and not just present relation of non-coordination.

Dialectical interpretation of that notion differs in this case from that of everyday consciousness, common sense, - and formal logic, as well. From the position of dialectics, contradiction is not an anomaly and/or incompatibility of alternative judgements, but on the contrary it is the combination of opposites. Contradiction of the object serves as a starting point of its development as its self-motion, and correspondingly a starting point for investigation of dialectics' subject. According to dialectics, every phenomenon possesses inner contradictionness (Widersprüchlichkeit), as a unity of opposites. Opposites inside an object are at the same time alternative and interpenetrative, inseparable one from another. Due to it the object is in contradiction with itself, Zlotina says. Just as development is not just change but the unity of change and preservation, contradiction is not just incompatibility, but the unity of incompatibility and inseparability. Contradiction is not a relation of difference, but a relation of identity of different, or difference of identical.

Contradiction as the source of development is determined by characterizing not the opposition of different essences, but a division inside the essence of one object. As the essence of phenomenon is thus presented as a differentiated essence, the phenomenon undergoes the process of its development, its self-motion. But at the same time, due to the unity of its inner opposites, the phenomenon also preserves its integrity. "Self-motion of the phenomenon is nothing else than the process of its self-reproduction carried out on the basis of correlation of its own 'elements'. A system (nature, living organism, society), being the unity of opposites that intercause, intercondition and intersupplement each other, does not need any outer force to set it into motion, as it contains that 'force' in itself" (Zlotina 1969: 59). In other words, contradiction in the object appears as the source and the ground for development. The divarication of the one allows the formation of the grounded out of the ground. Development as the process of such motion is determined by the unity of two opposites: differentiation (that is, division of one into opposites) and integration (the unity of opposites as preservation of the integrity).

At the same time, the inner contradiction, the inner source of self-motion is realized as a process in relation to outer factors as conditions of the development. The category of the inner like other reviewed dialectical categories requires accurate definition due to its polysemy. The outer in relation to the given object can be presented as both conditions that caused the object and products caused by the object, as well as proper 'outer' as everything that has no direct relations to the object. That's why, as noted by Zlotina, 'outer contradictions' cannot be defined as just contradictions between objects.

Firstly, in relation to the initial inner contradictions of the object all other contradictions will appear as outer ones, including those that are forms of manifestation of the inner. In this case the contradiction of the essence is shown as a contradiction between phenomena opposite by their essences. The outer, while it 
reflects the essence, also contains something 'inessential' that corresponds to concrete conditions of the manifestation. Secondly, outer contradiction can be a contradiction between the given phenomenon and conditions that caused it ('organism / medium'). That is, here the outer is not a moment of the inner. But on a larger scale (like considering 'the living nature' in relation to the 'organism / medium' opposition) this outer contradiction would nevertheless appear as the inner. One more specific kind of such outer contradiction is the contradiction between cause and caused: it is at the same time outer in relation to the caused and inner in relation to the general system. Finally, there is proper 'outer' contradiction as a relation of untied opposites that can condition the development of the phenomenon just like any kind of chance (in the everyday meaning of that word).

According to Zlotina, the categories of inner and outer present the features of development from the point of its formalization. Here inner is not identical with content, nor outer with form. The form of the phenomenon appears both inside and outside. The inner form arises in the ground of the object as a formalized content; the outer form is developed under the impact of conditions. The inner of the object reveals the process of unfolding its initial contradiction. Zlotina repeatedly stresses that the categorical distinction of inner and outer in no way means lesser importance of the outer in relation to the inner (as it follows from a nondialectical understanding of outer as accidental). It is exactly the outer that is a factor in the individualization of the object, an expression of the correlation of immanent inner development process and the impact of realization conditions of that process. The outer is the next, even higher stage of concretization and completion of the formalization process of the specific phenomenon.

The investigation of the correlation between inner and outer in the development process points to a question of the nature of general and its relation to the category of specific (particular). The universality of dialectical laws as reflection of the essence of all phenomena (as presenting the motion of matter motion in a whole) is not in turn something immutable. According to dialectical materialism, change also relates to the general itself, to laws themselves. And that's why the laws of dialectics appear as universal, as it was already mentioned. Zlotina notes that in relation to this issue there are also extreme points of nondialectical approaches revealed - either reduction of dialectics to 'a sum of examples', that is absolutization of the specific and denying of the general, or considering the general as 'a principle' practically independent of the specific.

However, "the general from the position of materialistic dialectics exists in the specific... only as specifically general" (ibid.: 84). Materialistic dialectics does not set its task in elaborating naturphilosophical scheme of 'one world process'. The dialectics of nature just points out that the theory of development of nature has to determine its specific subject by itself, thus causing a back impact on the general theory, enriching it with new ideas. On the other hand, philosophical ideas that generalize research results of specific sciences are also capable of rendering the latter assistance in working out concrete problems. In the same way, on different levels of the motion of matter, the specificity of development process manifestation is revealed in the form of specific correlations of inner and outer. For example, a living being, the biological form of motion, resolves the contradiction of inorganic matter exchange between 'the concrete-qualitative formation' and 'the environment' through acquiring some selfdependency in relation to the latter; however a living being itself becomes dependent on the environment, being obliged to adjust itself to the environment. A human (the social form of motion) does not only adjust himself to the environment, but rather adjusts the environment to conditions of his existence. Society begins its development on the ground of its own social contradiction that is also a specific manifestation of 'matter exchange' between nature and society.

Thus it can be concluded that development as the motion of contradiction, as the interaction of opposites inwardly peculiar to phenomenon is determined in its concrete content by the specificity of each concrete form. But this specificity appears just as the specificity of the general. The specificity of phenomenon manifests its quality and its integrity at the same time. Due to its inner contradiction, phenomenon, besides its qualitative integral unity, also possesses some division, separation in itself. This condition is the ground of manifestation of the category of quantity, paired to quality. According to Zlotina, the category of quantity is shown as a moment of cognition of the quality itself, its defining as a measure it is an aspect of the quality in its relation to itself (as of whole to parts). In cognition it is reproduced as 
different levels of object analysis: thing as itself, thing as system's element, etc. As knowledge moves to its higher levels the connection of quality and quantity becomes more direct and acute. This is reflected in the universal dialectical law of transformation of quality into quantity and inversely.

The development process is accomplished by transformation of quantitative changes into qualitative. The inner content of this process is the contradiction of steadiness and changeability that eventually leads to violation of measure. As categories of quality and quantity reproduce the relation of thing as integrity to differences inside the integrity, qualitative and quantitative changes differerentiate as changes of the thing itself (qualitative changes) and changes (quantitative) inside the given thing. Dialectical bifurcation of the thing in its qualitative and quantitative distinctness is overcome by the synthesis of those two sides as the transformation of quantitative in qualitative and inversely.

Development of phenomenon out of inner contradiction through intertransition of qualitative and quantitative changes shows the nature of development as the unity of change and preservation that in turn constitutes the essence of another law of dialectics - the law of the negation of the negation. In general, according to Zlotina, "The three fundamental laws of dialectics correspondingly state different sides of the objective contradiction of development (contradiction as the identity of competing opposites; contradiction as the intertransition of opposites that cause qualitative change; contradiction as the synthesis of change and preservation). In other words, laws of dialectics correspondingly form essence as the ground, the content and the form of development" (ibid.: 158-159). And at the same time both the content and the form of development are determined by essence.

The negation of the negation is simultaneously the process and the result of contradictionness (Widersprüchlichkeit) of phenomena, the form of their motion. The negation is the transition of the phenomenon into its opposite as a result of its inner contradiction. The negation of the phenomenon uncovers the regularity of inner connection between stages of qualitative changes of the object, when development manifests itself as advancing ascension that anticipates a certain kind of repetition of the initial phase of development on higher level.

The point is that during the transition of phenomenon into its opposite it ceases to exist as the given fixed qualitative phenomenon. However the negation of the quality as the negation of the integrity of phenomenon cannot mean simultaneous negation of all its elements - it is just the preservation of certain features of the object. In other words, the negation is not only a breakup in the process of the object development, but also a bond of different stages of this development. The negation is not an outer negation; it reflects only the self-motion of the object, its development out of the inner contradiction. The abolishment moment in the form of the negation is the abolishment of anything that prevents the process of further development of the object. And, in Zlotina's words, the developing phenomenon itself as a contradiction is inevitably to come to the self-negation of its historically fixed qualitative specificity.

Let us pay attention more precisely to the correlation of categories of specific and general, parts and whole. Parts and whole correlates with processes of differentiation / integration: a part, or element, is a result of differentiation, and the whole is a result of integration. At the same time the development of the ground is the development of the whole (and that does not mean assembling of the whole out of parts, but a motion of undeveloped whole to the developed whole). It is natural that an element takes an immediate part in this development, but a part is not being developed into a whole, but into a part of a whole.

Generally speaking, the dialectics of part and whole makes us turn again to the very important, in my opinion, moment of particular, concrete. In this case, upon referring to concrete, the category of the whole and the integrity (as the property of phenomenon's becoming as a whole and the property of its present being as a whole) correlates with the category of totality defined by Hegel as "unfolding in itself and preserving the unity" (Hegel 1974: 100) ${ }^{3}$. As noted by Irina Dobronravova, "if we approach an element as an outside-manifested totality, it obliges us to correspondingly consider it from within as concrete" (Dobronravova 1990: 65) - that is, the whole as a totality is revealed in the form of concrete.

I think it means that diversity of the mentioned possible consideration of each phenomenon (thing as one whole - thing as the system of parts - thing as the part of a system) displays this phenomenon as a

3 “...konkret nur als sich in sich entfaltend und in Einheit zusammennehmend und -haltend, d. i. als Totalität...". 
totality, as the self-motion process of the whole. The whole here is revealed not as general but as specific, but this specific is concrete-universal, and not singular. It would be appropriate here to use the category of particular (Besondere). For Hegel, particular is instead an intermediate link between singular (Einzelne) and universal (Allgemeine); the knowledge is shown as ascension from singular through particular to universal. On the other hand - and this point of view would be more adequate to dialectical philosophy of Zlotina - universal reveals itself just in particular. Particular (as concrete-universal) is the final result of knowledge process, opposite to the abstract-general that mediates the motion from singular to particular.

Let us repeat that the general itself becomes apparent as specifically general. It is the particular - as the unity in diversity - which serves as the singular that carries universal in it. The latter cannot practically exist on its own and is revealed as just a moment of the particular, so as later in the motion of knowledge it would be marked out as general. It is appropriate to quote a wonderful picture of knowledge motion drawn by the great Russian philosopher Father Pavel Florenskiy: "Worldly Weltanschauung deals with the singular... The science... splinters the singular, then the abstract arises, - the general, stiffened in its sacrificial plurality. But dialectics melts down bonds that secure in immutability - though not life, but only its phantom. Then flows unfettered plurality, and, on running, coils again into the singular, but now it is not one of singulars, but the singular predominantly - the singular that embraces singulars. It is the universal" (Florenskiy 2000: 136-137).

The unity of the world as the unity of diverse - here Zlotina sees the initial point of materialistic dialectics and objective contradiction of the material world. "Things that possess qualitative specificity and quantitatively differ between themselves at the same time happen to be identical in something; qualitatively concrete form of a thing's existence appears as a manifestation of something common to all things; the finite thing by its identity with others reveal its infinity; while disappearing, it preserves itself, etc." (Zlotina 1969: 205-206). It is the discerning of the matter as the ground of general and specific, one and many and other 'paired-categorical' moments that is, by Zlotina, the process of matter motion as the process of change of what remains preserved. Such differentiation, such matter's discerning in the process of development reveals not as antinomicity but as concrete identity of opposite things as moments of one process: "Each thing concentrates its history in itself: as a singular it appears as manifestation of the general, as finite - of the infinite, as transient - of the steady, as appearance manifestation of essence" (ibid.: 206).

\section{Development as the process of essence's appearance. Determination and self-determination}

The consideration of the development process as the motion of thing out of its contradiction leads us to the necessity of investigating essence in its correlation with the paired category of appearance (Erscheinung, phenomenon). Essence and appearance are two sides of the contradictory being of all things; essence reproduces the object's development process in its necessity (laws of dialectics), while appearance is the real development process determined by both laws and conditions of development. The phenomenon contains moments that supplement the necessity and thus add to the phenomenon the originality of the singular.

In general, the issue of concrete forms of development as results of contradiction could be finally reduced to the issue of how necessary becomes actual (wirklich) - and that is the problem of how essence appears (becomes appearance). Essence and appearance are the two sides of development process: essence reproduces the continuity of that process, and appearance reflects its realization through breaks of the continuity. The sphere of essence corresponds to the sphere of general, identical, infinite; and the sphere of appearance is the sphere of singular, differentiated, finite.

But the categorical differentiation of essence and appearance cannot be reduced to their opacity, to the differentiation of 'phenomenon' and 'noumenon' in their antinomicity (as cognizable and incognizable, as 'outer' and 'inner', etc.) - now, many years after Hegel, one can still meet such antidialectical interpretation of these categories). The dialectical relation between essence and phenomenon is the relation of essence to itself in the course of the development process. Essence is not located outside 
appearance; phenomenon as appearance of essence is the development of the essence itself. The development out of contradiction is related both to appearance and essence.

Essence as concrete general (and not abstract general) is the process of its appearance through contradiction of general and specific, inner and outer. If essence is to be considered as only one of its own moments (like just general, inner, etc.), then essence is indeed found to be an antinomy to appearance and an empty abstraction. On the other hand, appearance is also often interpreted as outer, 'chance' etc. - but in truth appearance turns out to be richer than essence due to originality and diversity of concrete conditions of its development. That is, in Zlotina's words, "appearance is essential as an appearance of essence, and does not coincide with essence as its appearance" (ibid.: 214).

Essence is revealed in diversity of phenomena as the unity of this diversity. On the other hand, the lack of coincidence of essence and appearance as results of the object development displays the double determination' of the phenomenon in its development. In other words, phenomenon is developed in correlation with other things and as a result of its development it manifests not only its own essence, but the essence of that correlation as well. At the same time every phenomenon involves essence: the connection of these categories is of a universal nature.

As it has already been noted, the category of essence reflects the necessity of the development, laws of dialectics - and this moment requires more precise consideration. On the one hand essence as the ground is the necessity, while appearance as the grounded follows out of it; but on the other hand the grounded is richer than the ground. The necessity of the one and essential is supplemented by and concretely realized in appearance through plurality of conditions and interaction with other things. This state of affairs brings up an issue of determination and forces us to consider the next pair of categories necessity and chance.

The category of essence is of the same order as the category of law, however they are not identical with each other. Laws appear as reflection of a tendency that constitutes the necessity of connection in the process of essence's development. Essence appears as the necessary ground out of which the grounded appearance follows. A law also correlates with phenomena as something that reflects the essential in phenomena while surely not enclosing phenomenon as a whole. At the same time a law as a tendency has its effect under certain conditions, and hence a law depends on those conditions - the effect of law does not coincide with its tendency. That's why laws have their effects on phenomena not directly but through a complex system of interconnections. Neither does the real concrete development process coincide with the abstract tendency laid inside the law.

Laws, as stated by Zlotina, belong to a sphere of self-determination of development, which is realized through the contradiction of 'inner' and 'outer' determination. The real determination process can not be reduced to single-meaning causality. The effect contains, besides the ground as a tendency of necessity, also a plurality of factors that express concrete conditions. The concrete ground of a concrete process irrespective of conditions is but an abstract possibility of realization of necessity contained in it.

Here we must note the illegality of the two extremes - fatalism as an incorrect conception of complete predetermination of concrete development process by the law (necessity), and the opposite extreme point of indeterminism that denies necessity and states the possibility for development to be carried out in any way in the presence of a certain ground. In fact, the development process possesses features of both as a process of contradiction of opposites - necessity and chance. By keen Zlotina's remark, "As the ground contains necessity in the form of possibility, the development is not carried out in a single-meaning way. But as there is necessity contained in it in the form of possibility, it is carried out in definite direction (ibid.: 226).

The tendency, the direction of development process is given by a quite definite contradiction of the thing that is being developed, and there's the manifestation of necessity. And owing to the fact that the real development process is realized by a contradiction of inner and outer determination, necessity takes the form of chance. Chance, as a manifestation of necessity, is the idea that is famous since Hegel's times and at the same time it follows out of the very nature of necessity, according to materialistic dialectics. Necessity is simultaneously not only the inner immutable tendency of a thing, but also its characteristic 
from the perspective of process and activity: the developing thing is not only defined by outer conditions, but it also transforms those conditions corresponding to its inner tendency in the course of its development. That's why, particularly, the development process of the living from the position of its determination still cannot be considered as one of the two mentioned extreme points.

We must note that such a theory of dialectical connection of chance and necessity is very adequate to the contemporary situation of philosophy of science, when philosophers try to find a methodological explanation for phenomena that become objects of present-day science, and particularly self-organization processes. Despite use of other terminology, contemporary thought comes to the same conclusions regarding determination as traditional materialistic dialectics - like the 'incomplete determinism' conception of W. Hofkirchner.

On the other hand, I. S. Dobronravova uses the dialectical approach while investigating determination of complex systems' self-organization processes. Upon considering existence as appearing out of the ground - and that is Zlotina's approach - determination of this existence is carried out both by the ground and by conditions, and by the way the ground assimilates conditions as well. It would be incorrect to state that in a bifurcation situation (when the developing system 'in a chance way' makes a choice, for instance, of one of two possible options for further development) the choice does not depend on the ground, and probabilistic causality is insufficient here.

First, the chance choice is realized out of a given set of options. That is, on the one hand, the choice is chance as it is determined by fluctuation (a spontaneous deviation of a certain parameter from its average value that leads to a change in evolution path) - in a critical situation the actual state contains equally possible options. But at the same time any one of chosen paths appears as necessary, for it is determined by the actual state of the system before such a phase transition. That is, according to Dobronravova, under any variant of choice necessity has its ground and realization conditions, and besides both the fluctuation value and the situation of choice itself are objectively grounded (Dobronravova 1990: 106).

Thus, the approach of materialistic dialectics that states concrete interaction and subsidiarity of chance and necessity is found to be quite justified and effective in the situation of contemporary science. But let us come back to the criticism of dialectics from the side of 'red existentialism' that we mentioned earlier. The point is that dialectical determinism springs from the knowledge sphere and not reality; the freedom in dialectics' world with its interosculation of opposites, in I. Bychko's words, "is not chosen but imposed", as the mind can only freely choose out of real options that have their realization conditions already developed. In other words, in the manner of S. Kirkegaard and J.-P. Sartre, real choice is possible only when the two options would not become reconciled but one option would overcome the other, and they must not arise from the knowledge system but be built up by creative spirit's will.

Let us again note here the antinomical approach to categories (particularly, freedom / necessity, or necessity / chance). Firstly, as it is evident from the self-organization examples reviewed, a system (including living organisms) possesses a considerable level of freedom while choosing one of several options at a bifurcation point. Such possibilities are quite concrete and they arise in actuality and not in cognition.

Secondly, the point of view that states that freedom is limited by initially inherent necessity moment (the tendency of essence's development) is wrong as well, due to a false approach to the category of essence - it is considered as abstract and not concrete as it is seen by materialistic dialectics. The point is that, as it was already said, concreteness as unity of plurality could not be posed by ready essence; essence itself contains plurality of conditions faced by the appearance of essence during its development process. And that's why, on the other hand, the category of freedom itself has sense only with respect to the category of concrete necessity. As Zlotina states, "Only regarding necessary concrete ground something can be considered as necessary or chance, essential or inessential, actual or non-actual, etc." (Zlotina 2001: 27). For essence is not only essence as the ground, but as the grounded as well; essence is both the determination process and the result of that process.

In other words, in the course of essence's development process both 'self-determination' and 'determination by conditions' are aspects of proper self-determination! Because any determination by conditions, that is, 'outer' determination, can become a determinative factor only by means of refracting 
itself through the inner nature of thing. As was already remarked, paired categories receive concrete content only in the system of categories, and that's why from the position of materialistic dialectics its very consideration as antinomical (for instance, in existentialism) is nothing but groundless.

Unfortunately critics of dialectics and representatives of dialectical philosophy are incapable of coming to an agreement due to different interpretations of categories that are often being used, as Zlotina says, in their non-categorical meaning. Ideas of free creative work and teleology advanced by contemporary thought do not conflict with materialistic dialectics, although in the old 'Dialectical Materialism' textbook there were flat statements that "there are no causeless phenomena" or "teleology is an enemy of science" (Alexandrov, 1954: 77, 86). Not to mention unjustified ontological use of dialectics shining through cited formulas, causality as evident from the preceding consideration does not enclose whole determination process and does not expel chance as demonstration of freedom. And that's why such theories as, for example, V. Nalimov's spontaneity conception, which defines spontaneity as the lack of causality and at the same time pictures it as creative self-organization and unpacking of potentially hidden in nature, do not conflict with dialectics. But this statement requires more precise consideration of creation in the development process.

\section{Development and creation. Cognition and reflection}

In Zlotina's dialectics the reflection conception occupies one of the major places. It used to evoke special criticism: reflection has often been considered as something passive, vulgar-materialistic. The late Vladimir Shinkaruk who for many years was the director of the Philosophy Institute of Ukraine Academy of Sciences, in his article contributed to a collection of works dedicated to Zlotina's anniversary, points out the following features of the Kiev philosophy school approach. Both priority research directions (logic and philosophy of science - and problems of human, Weltanschauung and culture) that take their origins from Kopnin, are featured according to Shinkaruk by "Introduction into the foundation of the problem of solving the unity of thinking and being, spiritual and material, - instead of the so called Lenin's reflection principle (Lenin's theory of reflection), - the activity principle... That principle overcomes the notion of singlemeaning determination of the present by the past and the future by the present. The connection between them is carried out not through the effect of objective laws independent of human, but through his, human's, own activity that is free as it is capable of rising over circumstances... and creating new actuality that in many respects is not derivative from the activity circumstances, that is from the past" (Shinkaruk 2001: 45-46). Activity is considered here as broader category than traditional conception of practice; activity presupposes the freedom of choice out of alternative possibilities, thus picturing development, in Shinkaruk's words, in a new perspective not peculiar to Marxism.

In truth, the activity approach is really one of the most prominent features of the Kiev school of philosophy, and Zlotina (who was not Kopnin's pupil) pronounces that idea in her process approach to dialectical categories. At the same time one must note that the activity approach was not exclusive to the Kiev philosophy school; it was effectively employed in other philosophical centers of the USSR. Besides, there is no special contradiction to Marxism as the very notion of activity was laid out by Marx and Engels as the criterion to approach investigations of the dialectics of nature. Thus, Engels notes the disdain of human activity by his contemporary science and philosophy that "only know nature on the one hand and thinking on the other hand. But the most essential and closest ground for human thinking is just the change of nature by human, and not only nature as such but human mind as well has been developed accordingly to how man learned to change nature" (Engels 1964: 198) ${ }^{4}$. At the same time, according to Engels, we must not make an absolutization out of activity as our domination over nature: in fact we do not rule over nature, on the contrary, "we, with flesh, blood, and brain, belong to nature, and exist in its midst,

\footnotetext{
4 “...Sie kennen nur Natur einerseits, Gedanken andrerseits. Aber grade die Veranderung der Natur durch den Menschen, nicht die Natur als solche allein, ist die wesentlichste und nachste Grundlage des menschlichen Denkens, und im Verhaltnis, wie der Mensch die Natur verandern lernte, in dem Verhaltnis wuchs seine Intelligenz".
} 
and [...] all our mastery of it consists in the fact that we have the advantage over all other beings of being able to know and correctly apply its laws" (ibid.: 154) ${ }^{5}$.

Another thing is that sporadic remarks by Engels were systematically studied by Soviet philosophical thought and were reflected, in particular, in Zlotina's system of dialectics. And the reflection principle was reviewed by Zlotina just from the position of the activity approach: while old ("metaphysical") materialism considered reflection in an abstract meditative plane, dialectical materialism originates from the principle of a subject's activity (that point has been already stated by Kopnin himself). According to Zlotina, the very logic of subject is a result of interaction between subject and object, so reflection is not a simple copying of actuality but a process of its specific transformation through laws inherent in cognition and in forms that correspond to it. Here lies the contradiction of subject and object: on the one hand, humans can only subjugate and transform the surrounding nature when they obey its logic. But thereby they deny that natural logic while transforming it with their own activity. The cognition is being 'objectified', and the object is being 'humanized'.

The noted contradiction serves as the source of knowledge motion. Materialistic dialectics considers the reflection principle as a manifestation of the material conditionality of human thinking: there is nothing in thinking that is absent in practice. Thinking itself appears as an aspect of practice and cannot be reduced to the present being, while the history and practice of knowledge determine it. In that way dialectics as the theory of development 'coincides', for Zlotina, with logic as the method of formation of that theory, and with the theory of that method. The theory of knowledge is the theory of development of knowledge as reflection of objective dialectics of nature.

Again it must be stressed that the reflection principle does not deny the activity of subject but is based on it. Knowledge and practice, Zlotina underlines, are the two sides of the process of transformation of actuality, namely the spiritual and material sides of activity. Neither could knowledge exist without practice, nor practice without knowledge. This divarication of activity into identical interpenetrative opposites is the contradiction serving as the ground for human activity process. From the position of interaction between subject and object, it is material activity that is subordinated to goals of spiritual perception of the object in knowledge, while in practice the spiritual is subordinated to goals of material transformation.

The discerning between practice and knowledge from the absolutized epistemological position is just what is meant by the discerning between practice as creative work and reflection as copying of object. However, according to Zlotina, "Outside of this relation practice and reflection are aspects of one and the same process - practice, as material and spiritual transformation of the actuality - the creation" (Zlotina 1969: 275). Practice while transforming the object at the same time reflects it, because it follows that object, its own inner logic. Reflection while following the object transforms it in a spiritual way. Reflection as a process is practical interaction between subject and object, reflection is creative work, and, as Zlotina states, only as a creation is it reflection of real actuality, that is, dialectics of nature. The result of reflection is an epistemological image of the object, which is not a copy of the actual object, but a total of its one-intwo transformations, both theoretical and practical, which corresponds to the essence of the knowledge process. Knowledge, practice, and creation are different motion forms of the contradiction of human transformation activity. But the ground for the development of the contradiction is still practice.

Before we turn directly to investigation of the category of practice let us pay attention more precisely to the category of creation, which was researched in detail by Zlotina in 1970s and 1980s, after she completed her Doctor of Science dissertation. In the most general sense creation means activity aimed at making something new, new results or new ways of achieving those results, and in such abstract form creation is diametrically opposed to 'activity by standards' that does not carry any elements of novelty. However, according to Zlotina, such polarity is but one-sided and outer in respect to creation. From dialectical point of view creation opposes not only 'activity by standards' but also another extreme chaotically arbitrary activity that totally lacks any standards.

That is the where the inner contradiction of development lies, being reflected in creation. The singlemeaning determination of determination by standards appears as one moment of opposite activity

\footnotetext{
5 “...Wir mit Fleisch und Blut und Hirn ihr angehören und mitten in ihr stehn, und daß unsre ganze Herrschaft über sie darin besteht, im Vorzug vor allen andern Geschöpfen ihre Gesetze erkennen und richtig anwenden zu können".
} 
described by Zlotina as "polysemantic (ambiguous) determinism". Hence creation is shown to be the process of dialectical freedom / necessity contradiction being solved: creation is free activity regulated by objective laws. The freedom of creation therefore opposes not inner determinism (owing to which creative work can be carried out as an activity) but outer regulations: the freedom of creation is in fact "the freedom from anything incompatible with objective determinants of the creative process" (Zlotina 1987: 99).

Thus, creation cannot objectively exist without any standards, although, Zlotina remarks, separate activity act (but not its methodological reflection) can assume individual forms of both extremes, activity by standards and activity by arbitrariness, and can even be theoretically reproduced in corresponding ways of thinking - 'dogmatism' and 'voluntarism'. However, as an objective process creation never ceases to unite freedom and necessity. It is not an abstract, but a concrete necessity that becomes actual, being determined by essence of the object, its activity, and conditions of its development. Criteria of creation, as stressed by Zlotina, cannot be abstract, they are always concrete: the new as a result of creation is a new that belongs to a sphere of quite concrete essence. Thus, scientific creation must remain within the limits of the scientific, artistic - within the limits of the artistic, etc., otherwise the new created would not be considered by us as new at all.

The knowledge also appears as theoretical process, as reflection of actuality, as a subjective way of solving the subject-object contradiction. In the course of the knowledge process universal methodological development laws are being reflected in the cognitive abilities of subject. That is, for Zlotina, "Being determined by laws of an object, cognition as the process of interaction of subject and object reproduces these laws in its own motion in accordance with subject's peculiar properties and finally reflects these laws as objective laws of real actuality" (Zlotina 1969: 281). Zlotina describes the general regularity of the knowledge process as dialectical motion from appearance - to essence - and to their unity, from experience (as living contemplation) through theory (as abstract thinking) toward practice.

Perceptive, rational and practical are the three 'stages' of cognition, according to Zlotina, and that's the distinctive feature of her dialectical system, for traditionally in Soviet philosophy practice was opposed to knowledge, and the latter was limited to two stages - empirical and theoretical. However, Zlotina demonstrates that practice is not only 'the third phase' but also the ground of the knowledge process, its 'beginning' (as empirical experience) and its 'end' (as experience passes through its transformation into theory's other-being, as spiritual reproduction of experience, and reaches the level of deliberate realization of theory). Experience is perceptive material activity; its result is reflection as perceptive concrete image of object. Theory is a process and a result of spiritual transformation of object reflected in the notion as theoretical image. Practice is "a process of objectification of theoretical knowledge that also gives a practically reproducible 'image' of an object" (ibid.: 284). The motion of object's image reproduced in the knowledge process is carried out from direct actuality - through ideal actuality - toward real actuality.

This logical order of stages also describes the process of cognitive relation of subject to object, and the process of historical development of science, and the process of resolution of subject-object contradiction. As stated by Zlotina, the motion from object - to subject - and to their unity is realized in accordance with specificity of stressing one of indicated 'stages', however within each of them there is also a similar motion taking place. Knowledge can appear only as the unity of sensation, thinking and practice, and each one of these stages is included in the truth formation process. On the one hand, interaction of sensation, thinking and practice is continuous cognitive process as the contradiction being resolved. On the other hand, as discontinuous, due to predominance of one of the three moments, this motion appears in each of the three stages in its specific form.

However here again, as it was noted earlier, the ground for the motion is practice that is also the ground of transition from living contemplation to abstract thinking. Thus, empirical sensation while reflecting a thing represents it as a sum of singularities. In the course of practical verification the sensation itself discovers inconstancy of the singular. And here human knowledge, Zlotina says, grasps something that abides, something that exists outside sensations. On the ground of this contradiction there is a leap from sensation to thinking, from perceiving singular to perceiving general, which is mediated by practice. 
Abstract thinking does not exist as constructing the general, but it correlates with development of knowledge as the process of reflection. The general in relation to the singular appears here as essence in relation to appearance. That moment is the feature of materialistic dialectics as dialectics of nature, in opposition to statements of critics who see 'a contradiction in definition' in it. The general, as underlined by Zlotina, is not a product of human thinking - the general objectively exists in reality. But, as it was remarked earlier, it does not exist by itself, but only in and through the singular, while being reflected as the general already in the motion process of human knowledge.

Within the motion of knowledge on its theoretical level there also is a motion from abstract to concrete but it is concrete in thinking, and although it reflects the object in all diversity of its aspects it is itself an abstraction. The objective truth of abstractions formed on the theoretical level of knowledge can be provided only by the withdrawal of knowledge outside thinking - its transition to practice, to realization of knowledge. The contradiction of abstract thinking that is being resolved in practice appears, for Zlotina, as a contradiction "between perceptive knowledge of appearance and the abstract form of comprehension of essence" (ibid.: 302). That is, the logic of abstract thinking itself turns out to be formal in respect to the concrete object. It is this contradiction that is resolved by practice, which forms are determined by the nature of concrete things themselves and which serves as the ground of the concreteness of knowledge.

Thus, practice constitutes a stage of cognition; but at that practice is broader than cognition itself, so that within it practice accomplishes the specific function of the criterion of truth. At the same time practice does not only verify finished thinking results but it also introduces the new while checking and concretizing those results. It is incorrect both to identify practice with knowledge and to contrast these two categories. Dialectical consideration shows the interdependency and interosculation of knowledge and practice.

\section{Conclusion. Maria Zlotina's dialectics and the present}

As was noted in the beginning of this paper, the present-day revival of interest in dialectical philosophy is caused by the development of science. In that way the science itself refutes the criticism of dialectics from both 'red positivists' and 'red existentialists' who see dialectics of nature as nothing more than a centaur. The scientific vision of nature underwent essential changes starting from the end of the last century. The classical conception of nature as a dead, soulless and simple mechanism that obeys reversible, strictly deterministic and timeless laws is being replaced by a more complex, multileveled one that is described in terms of temporality and irreversibility, chance and plurality. According to the saying of one of creators of contemporary scientific paradigm, llya Prigogine, that he stated in his famous work "Order out of chaos" written together with Isabelle Stengers, "Matter is no longer a passive substance described in the frames of a mechanistic world picture, it also possesses spontaneous activity. The difference between the new world outlook and the traditional one is so deep that... we can on full ground talk about a new dialogue between man and nature" (Prigogine 1986: 50).

Undoubtedly this new view of nature truly corresponds to that of dialectics, particularly to the reviewed conception of dialectical materialism. Consideration of matter as an active substance and the world as undergoing self-organization out of chaos to order marks the introduction of the conception of becoming into science, especially physics. As noted by Prigogine, the denial of that conception by classical science used to lead not only to alienation of science from philosophy but also to a deep inner disunity in the science itself. Evolutionism, irreversibility and becoming, as aspects of reality that exist alongside being, upon entering contemporary science thereby bring it closer to humanities and other forms of cultural creativity.

The rise of the new scientific paradigm enables talking about cooperation and even unity of different spheres of human creative activity, and it is the science itself that reveals its need in philosophy and particularly in dialectics in order to ground and comprehend the new Weltanschauung. It is dialectical logic, according to Zlotina, that in distinction to formal logic appears as a logic of process, a logic of becoming and not the logic of functioning of a finished result (Zlotina 1975: 6-7). Dialectical logic does not expel formal logic, just as viewing the natural world from the point of its becoming does not expel the position of being, but supplements it as one of its moments, just like the 'single-meaning determinism' of 
classical mechanical physics appears as an inner moment, a simplified form of the 'polysemantic determinism' of nonclassical physics.

However the contemporary scientific situation is not finished by grounding the contradiction of two opposites, two sides of world outlook - classical and nonclassical, otherwise it would not correspond to dialectics. The philosophical reflection over present-day science fairly leads to elaboration of the conception of post-non-classical science ${ }^{6}$. The specificity of this new type of science is determined by radical changes in the fundamentals of scientific knowledge, compared to previous stages of science's development. In particular, complex self-organized systems are now objects of science; the ideal of scientific knowledge presupposes considering not only the object of knowledge (as in classical science) or the object and the methods of knowledge (that is a feature of nonclassical stage), but the subject of knowledge as well.

Without even appealing to the contents of contemporary scientific thought one can already note its purely formal accordance with dialectical logic: post-non-classics appears as a dialectical synthesis of thesis-classics and its nonclassical 'antithesis'. It is interesting that even those thinkers working in the area of philosophy of science and self-organization who do not use Styopin's terminology (it is in a certain way quite conditional) or are not aware of it, still construct their theories by trying to find some 'third way' while avoiding Scyllas and Charybdes of previous conceptions. Post-non-classical science is a way of getting back to classical unity while not losing nonclassical plurality: it is a unity in plurality, perfectly dialectical cognition of concrete-universal.

Getting back to reviewing the content of post-non-classical science, we can note that here contemporary philosophical conceptions are also dialectical. Three stages of cognition that Zlotina talked about correspond in her opinion to three stages of science's development. And although, no doubt, the notion of the $21^{\text {st }} \mathrm{c}$. post-non-classical science is not used in Zlotina's conception, there is a certain resemblance. The noted stages of knowledge also presuppose three stages of historical change in the object of knowledge. In the first level (that corresponds to empirical stage of knowledge) it is a thing by itself that is being considered, from the direction of its sensually perceived features. The second level of the development in the object of knowledge, which reproduces the abstract theoretical stage of cognition, picks up separate properties and relations of the thing studied. Finally the third and the highest knowledge level - that is, knowledge of the concrete - presupposes, for Zlotina, consideration of the thing as integrity, as a system (Zlotina 1969: 288).

The system approach along with consideration of systems from the position of their becoming and selforganization are distinctive features both of contemporary science as a whole and new scientific directions, such as synergetics. Synergetics is probably the brightest phenomenon of post-non-classical science that possesses the majority of its features - that is, paradigm of self-organization, paradigm of becoming, and the way out of the frames of science to humanities and cultural issues. Some philosophers, mostly from the Leningrad school, directly correlate synergetic with dialectics, considering the first as supplement to dialectical method that enriches its contents by new discoveries of science, particularly by defining the conception of development more precisely.

However it must be noted that synergetics in no way can claim to be a universal method or to replace dialectics, basing on new achievements in science and culture. Being an 'investigation program', in Dobronravova's term, though unusual, interdisciplinary investigation program, synergetic cannot pretend to universality. Even, for instance, Kiev philosopher Vladlen Lutay, who criticizes Dobronravova's position and tries to rise to a general philosophical summarizing of synergetic in order to create a new integrated world-picture based on synergetic ideas, which would enable us to find solutions to the $21^{\text {st }} \mathrm{c}$. problems, presumes dialectics as a method (Lutay 2003: 14).

The interdisciplinarity and even metadisciplinarity of synergetics, in my opinion, reflects such distinctive feature of post-non-classical science as its cultural orientation. The science can no longer be considered as absolutely autonomous from culture and such spheres like philosophy, arts, and religion. On the

${ }^{6}$ This conception was proposed by Vyacheslav Stepin in 1989 and is still being elaborated by many philosophers in Moscow, Kiev, and other centers. 
contrary, it is the whole cultural experience of humankind that forms the meta-context of scientific knowledge. In the old days dialectics had been often criticized for 'unjustified' expansion of general laws to such, it would seem, different areas as nature and society, and criticized for its claim to be a universal method of knowledge in both science and humanities. Contemporary science proves the relevance of the dialectical approach. In Shinkaruk's words, ideas of synergetic and universal evolutionism that penetrate today's science appear as "establishment of deep unity and even identity of dialectical regulations of development of nature, Universe, and human society..." (Shinkaruk 2001: 47).

Meanwhile the 'universality of the laws of dialectics' is an issue that still sometimes evokes a feeling of perplexity - note that the very notion of law is seldom used in contemporary philosophical thought. It is also concerned with the change in scientific view of nature, with deviation from deterministic laws: the term of 'scenario' is now being used in synergetics, etc. However, as it could be seen from Zlotina's conception, universal laws of dialectics have nothing to do with single-meaning deterministic laws in the sense of classical science. Universality (and universal significance) of dialectics is just its concreteness; its universality lies in that point that it demands considering not only abstract generality but each concrete moment individually, taking into account concrete conditions. For Zlotina, "Dialectical method in its concrete universality directs us toward investigation of the specific logic of specific object" (Zlotina 1975: 7-8).

Thus dialectical synthesis is being achieved, development as the motion of contradiction that denies extremes - fatalism / indeterminism, relativism / dogmatism, and so forth. Dialectics would be antinomical, would be reduced to insoluble pessimistic dichotomy, if it were limited by only postulating two opposites. Describing post-non-classical science, we depicted it as a unity of plurality in the dialectical sense. Here it is the moment of unity that is problematic, for the existence of plurality and denial of dogmatism are commonplace now and do not need any more proofs. However, assuming the unity, in spite of plurality, and certain 'return on a new level' to the classics is a distinctive feature of post-non-classical thinking that distinguishes it from that of post-modern.

The noted moment of unity is represented in post-non-classical science by the appeal to values and human culture. Systems of values, in Prigogine's pronouncement, are codes that keep the system on the development line, they "always resist the destabilizing effects of fluctuation..." (Prigogine 1991: 36). That is, values are the ground that allows the system to retain its unity in the course of the development process. This thesis is also present in dialectical conception of Zlotina and, in my opinion, it is one of the most impressive and bright points in her system that anticipates further philosophical investigation in the field of post-non-classics. Let us repeat: only in respect of concrete and necessary can something be defined as necessary or chance, essential or inessential, actual or non-actual. This universal regularity also concerns the sphere of human creativity.

Present-day Kiev philosopher Vitaliy Tabachkovskiy in his memoirs on the Kiev school of the 1960s recollects an occurrence that happened in his student years. One of his fellow students expressed a thought to a lecturer that the arguments of idealist philosophers are often non-less convincing than those of materialists. On that the lecturer replied, "Until you elaborate in yourself strict materialistic convictions, do not read those idealists" (Tabachkovskiy 2002: 167). Tabachkovskiy adduces this case as a gibe at the narrow-mindedness of the old Soviet materialists; however there is a certain 'rational kernel' in the lecturer's reply. After all, actually, only being a materialist can one ground the very opposition of idealism and materialism, only relying on ones own formed system of values can one value something as positive or negative, only possessing a certain scale, certain set of senses that constitutes a context of consideration can one perceive something concrete at all. And it is dialectics that, as already Pavel Florenskiy stated it, is concrete thinking in context, as opposed to abstract 'absolute formulas' (Florenskiy 2000: 141).

Thus, concluding this paper, we can make an inference that the best ideas of Soviet-time dialectical philosophy remain actual and effective. The dialectical method of knowledge based on the necessity of taking into account the specificity of the concrete is demanded by and is presumed by contemporary science and contemporary thinking in general. Conceptions of the prominent Kiev philosopher Maria Zlotina have not lost their theoretical profundity and practical significance in the $21^{\text {st }} \mathrm{c}$. 


\section{References}

Alexandrov, Grigoriy (Ed.) (1954) Dialectical Materialism [In Russian]. Moscow. Gospolitizdat.

Bychko, Igor (2001). Phenomenon of dialectics: the existential context [In Ukrainian]. In: Tabachkobskiy, Vitaliy (Ed.) (2001) Philosophical-anthropological studies' 2001. Reason, freedom, and the fates of dialectics (For $80^{\text {th }}$ anniversary of Maria Zlotina). Kiev. Stylos. pp 96-105.

Dobronravova, Irina (1990) Synergetic: the becoming of nonlinear thinking [In Russian]. Kiev. Lybid.

Dobronravova, Irina (2001) The contemporary need for dialectics and M. L. Zlotina's creative heritage [In Russian]. In: Tabachkobskiy, Vitaliy (Ed.) (2001) Philosophical-anthropological studies' 2001. Reason, freedom, and the fates of dialectics (For $80^{\text {th }}$ anniversary of Maria Zlotina). Kiev. Stylos. pp 125-135.

Engels, Friedrich (1961) Anti-Dühring [In Russian]. In: Marx, Karl, Engels, Friedrich (1961) Works. Moscow. Politizdat. Vol. 20. (English http://www.marxists.org/archive/marx/works/1877/anti-duhring/ch11.htm, German: http://www.mlwerke.de/me/me20/me20 032.htm).

Engels, Friedrich (1964) Dialectics of nature [In Russian]. Moscow. Politizdat.

Florenskiy, Pavel (2000) By the watersheds of thought [In Russian]. In: Florenskiy, Pacel Coll. Works: in 4 vol. Vol. 3, Part 1. Moscow. Mysl.

Hegel, G. W. F. (1974) Encyclopaedia of the philosophical sciences [In Russian]. Vol. 1. Moscow. Mysl. (German: http://www.hegel.de/werke frei/hw108004.htm).

Lutay, Vladlen (2003) Synergetic paradigm as philosophical-methodological ground for solving main problems of the $21^{\text {st }} \mathrm{c}$. [In Russian] In: Practical Philosophy. 2003. \# 1. pp 10-38.

Merleau-Ponty, Maurice (1964) Sense and Nonsense. Evanston, ILL. Northwestern University Press.

Prigogine, Ilya (1991) Nature, science, and new rationality [In Russian] In: Philosophy and life. 1991. \# 7. pp 34-38

Prigogine, llya, Stengers, Isabelle (1986) Order out of chaos [In Russian]. Moscow. Progress.

Shevchenko, Volodymyr (2001) The doctrine of progress and dialectics [In Ukrainian]. In: Tabachkobskiy, Vitaliy (Ed.) (2001) Philosophical-anthropological studies' 2001. Reason, freedom, and the fates of dialectics (For $80^{\text {th }}$ anniversary of Maria Zlotina). Kiev. Stylos. pp 258-273.

Shinkaruk, Volodymyr (2001) Dialectics: traditional and new approaches [In Ukrainian]. In: Tabachkobskiy, Vitaliy (Ed.) (2001) Philosophical-anthropological studies' 2001. Reason, freedom, and the fates of dialectics (For $80^{\text {th }}$ anniversary of Maria Zlotina). Kiev. Stylos. pp 43-52.

Stalin, Iosif (1941) On dialectical and historical materialism [In Russian]. In: Stalin, Iosif (1941) Leninism questions. Moscow. (English: http://www.marxists.org/reference/archive/stalin/works/1938/09.htm; German: http://www.marxistischebibliothek.de/histomat.html).

Tabachkovskiy, Vitaliy (2002) In search of the time not gone. Essays on creative heritage of Ukrainian philosophers of the sixties [In Ukrainian]. Kiev. Parapan.

Zlotina, Maria (1969) General laws of development and the reflection principle [In Russian]: Doctor of Science's Dissertation (Typescript). Kiev.

Zlotina, Maria (1975) On concrete universality of the method of materialistic dialectics (development and creation) [In Russian]. In: Questions of social sciences. Iss. 23. Actual problems of materialistic dialectics. Kiev. Vyshcha shkola. pp 3-10.

Zlotina, Maria (1987) Dialectic-materialistic theory of development - logic-methodological foundation for communist humanism [In Russian]. In: Zlotina, Maria, Yatzenko, Alexander, Osichnyuk, Euphim, et al. (1987) Philosophy of humanism. Kiev. Vyshcha shkola. pp 91-120.

Zlotina, Maria (2001) Main categories of materialistic dialectics (a lecture) [In Russian]. In: Tabachkobskiy, Vitaliy (Ed.) (2001) Philosophical-anthropological studies' 2001. Reason, freedom, and the fates of dialectics (For $80^{\text {th }}$ anniversary of Maria Zlotina). Kiev. Stylos. pp 20-35. 